\title{
Atmospheric Circulation Features Associated with Rainfall Variability over Southern Northeast Brazil
}

\author{
Rosane Rodrigues Chaves and Iracema Fonseca Albuquerque Cavalcanti \\ Center for Weather Prediction and Climate Studies, National Institute for Space Research, Sao Paulo, Brazil
}

(Manuscript received 5 December 2000, in final form 15 March 2001)

\section{ABSTRACT}

\begin{abstract}
The atmospheric circulation features associated with rainfall variability during the main rainy period of the region of southern Northeast Brazil (sNEB) are determined through principal components analysis and cluster analysis. Daily rainfall, NCEP reanalysis, and OLR data are used from 1979 to 1997 . The analyses are performed considering a large area including South America and the Pacific and Atlantic Oceans and also considering a regional area over tropical South America. The influence of synoptic systems, as well as the phenomena associated with their variability, such as El Niño-Southern Oscillation (ENSO) and baroclinic waves over the Pacific Ocean and South America are discussed. Positive (negative) rainfall anomalies over sNEB are related to cold (warm) episodes in the tropical Pacific. On the intraseasonal timescale there are interrelationships among the South Atlantic convergence zone (SACZ), Bolivian high, and the northeast upper-cyclonic vortex. It is noted that rainy periods in SNEB are associated with a northward displacement of the SACZ, an upper-level cyclonic vortex situated over the Atlantic Ocean, intense convection over the eastern Amazon, and an eastward shift in the position of the Bolivian high. At low levels the flow is directed from the Amazon toward the sNEB and there is a shift of the South Atlantic subtropical anticyclone eastward with a weakening of the southeast trade winds over the northeast coast. The dry pattern is associated with a southward displacement of the SACZ, an upperlevel cyclonic vortex either close to or over the continent, and a westward displacement of the Bolivian high. In this case, the low-level flow is directed from the Amazon to the south and there is a strengthening and/or westward shift of the South Atlantic anticyclone with an intensification of the southeast trade winds along the northeast coast.
\end{abstract}

\section{Introduction}

The region of southern Northeast Brazil (sNEB) is an area of approximately 1 million $\mathrm{km}^{2}$, located between $9^{\circ}-18^{\circ} \mathrm{S}$ and $37^{\circ}-46^{\circ} \mathrm{W}$ (Fig. 1). Most of sNEB experiences large spatial and temporal rainfall variability and the climate variations have important economic and social consequences. In contrast to the northern northeast, where the mechanisms that produce rainfall variability have been extensively studied (e.g., Hastenrath and Heller 1977; Moura and Shukla 1981; Nobre and Shukla 1996) the sNEB has, until recently, received relatively less attention from the research community. The knowledge of the rainfall mechanisms and its variability in this region, where the droughts are memorable and a recurring problem, is important in the search for better management of the agriculture and economy of the region. Intense precipitation over the coastal area, which causes sliding soil and loss of lives, is also a social problem and deserves attention.

Corresponding author address: Dr. Iracema F. A. Cavalcanti, INPE/ CPTEC Rod. Pres. Dutra, Km 40, CEP 12630-000, C. Paulista, SP, Brazil.

E-mail: iracema@cptec.inpe.br
The main rainy period of the sNEB is NovemberDecember-January, with maximum rainfall in December (Kousky and Chu 1978), associated with penetration of frontal systems or their remains to lower latitudes (Kousky 1979). At times, these frontal systems act to initiate and organize tropical convection over eastern Brazil (e.g., Kousky 1985), resulting in the formation of the South Atlantic convergence zone (SACZ), which features a band of cloudiness oriented northwest-southeast, from the Amazon region to the subtropical Atlantic Ocean (Kousky 1988; Kousky and Cavalcanti 1988). Another system that has a pronounced effect on the convection over NEB is an upper-level cyclonic vortex near the northeast coast. The genesis of the vortex is closely related to the development of a strong upstream upper-tropospheric ridge that intensifies because of lowlevel warm advection associated with an equatorialmoving cold front (Kousky and Gan 1981).

In the northern portion of sNEB the rainfall reaches a second maximum from February to April, as a consequence of the southernmost displacement of the intertropical convergence zone (ITCZ; Kousky and Chu 1978). Coastal areas receive their maximum rainfall from April to June associated with frontal systems and 


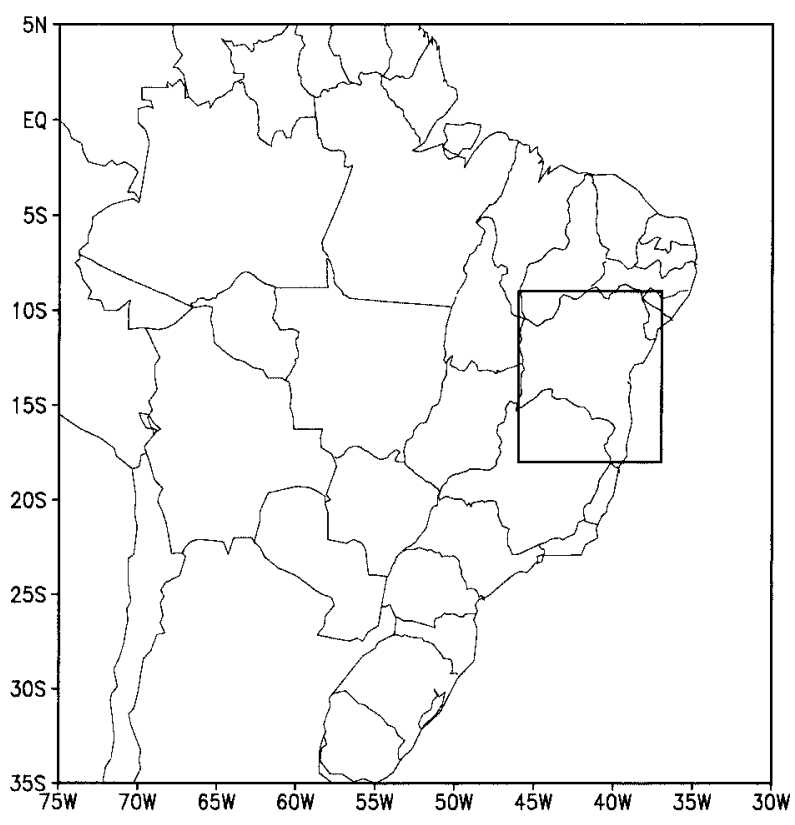

FIG. 1. The sNEB region: $9^{\circ}-18^{\circ} \mathrm{S}$ and $37^{\circ}-46^{\circ} \mathrm{W}$.

enhanced nocturnal convergence due to local land-sea temperature contrasts (Kousky 1979).

The sNEB experiences large spatial and temporal rainfall variability. Although the coastal area receives annually $1500 \mathrm{~mm}$ or more (Fig. 2), the interior receives rainfall between 400 and $800 \mathrm{~mm}$, values typical of semiarid regions. In isolated areas of this region the annual rainfall reaches values above $1000 \mathrm{~mm}$, associated with topography (Kousky and Chu 1978). In the western sNEB the annual precipitation reaches values above $1000 \mathrm{~mm}$, associated with the convection of the Amazon region. During the summer months western Northeast Brazil can be affected by the Bolivian high (Cavalcanti 1986). This system is characterized by an anticyclonic circulation in the upper troposphere, which is found climatologically near $15^{\circ} \mathrm{S}$ and $65^{\circ} \mathrm{W}$ (e.g., Tanajura 1996). The circulation results, in part, from the release of latent heat through convection (Silva Dias et al. 1983).

The climate of the NEB is associated with the local Hadley and Walker circulations. Anomalies in the Walker circulation can produce subsidence over the region that can also be affected by the large-scale subsidence associated with the Hadley cell when the ITCZ is displaced northward (Nobre and Molion 1988). The interannual variability of the NEB rainfall can be associated with El Niño-Southern Oscillation (ENSO) through combined effects of the variations in intensity and position of the local Hadley and Walker circulations. Negative rainfall anomalies occur over NEB in El Niño years (Kousky et al. 1984). Analyzing the interannual variability of the normalized rainfall anomalies, Rao et al. (1997) observed below or near average annual rainfall over sNEB for the El Niño years of 1983, 1987,

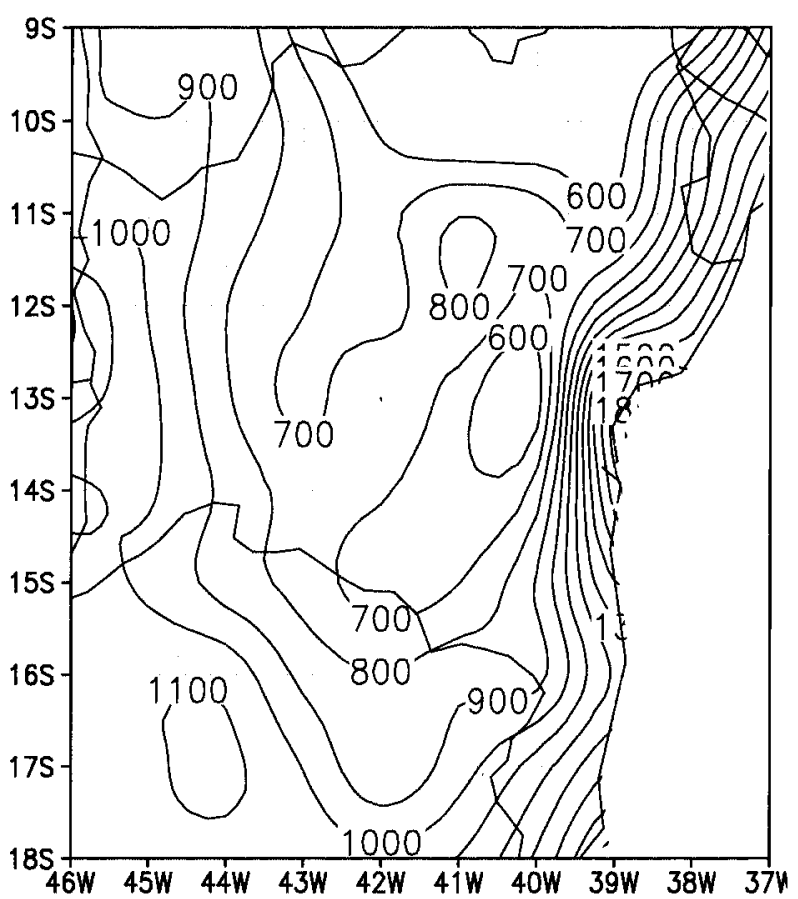

FIG. 2. Annual average rainfall (mm): 1979-97.

and 1992, and above average rainfall in La Niña years of 1984 and 1989 .

The purpose of this study is to objectively identify daily circulation patterns associated with different weather conditions in sNEB. Different circulation patterns produce different weather, and changes in the frequency of occurrence of these circulation patterns result in changes in the regional rainfall. Thus it is possible to explore the causes of change in rainfall by identifying daily circulation patterns responsible for different regional regimes and by analyzing the frequency of their occurrence and examining the relationship between the circulation patterns and regional rainfall. This analysis is performed through principal components analysis coupled with cluster analysis as in Zhang et al. (1997).

This paper is organized as follows. In section 2 the datasets and main methods used in this study are described. In section 3 the characteristics of circulation patterns associated with rainfall variability over the sNEB are presented and discussed. A brief summary and our conclusions are given in section 4 .

\section{Data and methodology}

\section{a. Data}

The rainfall data used in this study were extracted from daily station datasets obtained from the Brazilian National Agency for Electric Energy and Hydrological Resource Management of Bahia State. The station data were initially checked for missing data, and only stations with less than $5 \%$ missing data were considered. In this 
way 99 stations were selected from 1979 to 1997 and the missing data were estimated by interpolating data from neighboring stations. Daily analyses of wind at 850 and $200 \mathrm{hPa}$, relative vorticity at $200 \mathrm{hPa}(1979-$ 97), and specific humidity at $700 \mathrm{hPa}(1979-96)$ from the National Center for Atmospheric Research-National Centers for Environmental Research (NCEP-NCAR) reanalysis archive were used, with resolution of $2.5^{\circ}$ latitude-longitude (Kalnay et al. 1996). The third dataset corresponds to daily OLR data from National Oceanic and Atmospheric Administration/Cooperative Institute for Research in Environmental Sciences Climate Diagnostics Center (Liebmann and Smith 1996) with $2.5^{\circ}$ latitude-longitude grid from 1979 to 2000.

\section{b. Methodology}

To include features of the Pacific and Atlantic Oceans associated with the rainfall over the sNEB, the area from the international date line eastward to $0^{\circ}$ and $60^{\circ} \mathrm{S}$ to $35^{\circ} \mathrm{N}$ is considered in the atmospheric characteristic analysis. A regional analysis of the atmospheric variables is also performed, applying the method again to the area from the equator to $25^{\circ} \mathrm{S}$ and $85^{\circ}-20^{\circ} \mathrm{W}$ to highlight the characteristics of the systems that act over tropical South America. In both cases the average of precipitation in the area comprising $9-18^{\circ} \mathrm{S}$ and $37^{\circ}-$ $46^{\circ} \mathrm{W}$ is taken.

Principal components analysis (PCA) was performed coupled with cluster analysis to determine the atmospheric patterns associated with precipitation over the sNEB. The PCA approach identifies circulation patterns based on the magnitude and signal of the daily score for each principal component retained, while PCA combined with cluster analysis classifies circulation patterns by performing cluster analysis in the daily score for each principal component retained. The cluster analysis is the logical and most appropriate statistical tool for finding groups of meteorological fields that resemble each other according to certain assigned criteria (Molteni et al. 1990). In the literature examples of the use of cluster analysis include grouping daily weather observations into synoptic types (Kalkstein et al. 1987; Zhang et al. 1997) and defining weather regimes from upper-air flow patterns (Mo and Ghil 1988). Details of this method can be found in Wilks (1995, 419-427). The method of clustering used in this work is a $K$-means algorithm, based on Hartigan and Wong (1979). The objective is to find group definitions and memberships for a predefined number of groups, which minimize the sum of square distance within the set of the cluster. This method was also adopted by Mo and Ghil (1990) and Zhang et al. (1997). As shown by Gong and Richman (1992) this method coupled with PCA can provide the most separable system of cluster.

PCA was applied only to the daily anomalies of specific humidity at $700 \mathrm{hPa}$, relative vorticity at $200 \mathrm{hPa}$, and wind at 850 and $200 \mathrm{hPa}$. The precipitation data were used in the cluster analysis. The K-means method was performed in the time series of the first four principal components classifying each day in a determined cluster. The first four principal components were chosen based on the plot of the eigenvalues versus the number of the eigenvector. In the clustering criterion the correlation between the centers of clusters should not exceed a threshold taken as 0.36 (Mo and Ghil 1988). The fraction of the variance explained by the first four PCs was $7.7 \%$ for specific humidity, $7.2 \%$ for OLR, $9.5 \%$ for relative vorticity, and $13.3 \%$ and $14.4 \%$ for winds at 850 and $200 \mathrm{hPa}$, respectively.

In order to evaluate the link between the occurrence of a specific atmospheric pattern and rainfall, a performatic index (PI) of clusters was calculated (Zhang et al. 1997). The PI was used to determine the relationship between a specific atmospheric large-scale or regional pattern and the spatial average daily rainfall over the sNEB region. This index is defined as a measure of the relative contribution of a specific circulation pattern in the total amount of rainfall. The mean daily rainfall within cluster $i$ is compared with the climatological daily mean rainfall:

$$
\mathrm{PI}=\frac{R_{i} / n_{i}}{R / n},
$$

where $n_{i}$ is the number of occurrences of a specific pattern, $R_{i}$ the total amount of precipitation during these $n_{i}$ days, and $(R / n)$ represents the climatological daily average of the period of $n$ days. If $\mathrm{PI}_{i}$ is greater (smaller) than 1.0, the specific pattern has (has no) significant contribution in the precipitation of the considered period. Table 1 shows the PI, the number of elements used in the composites, and the number of elements of each cluster to the rainy and dry patterns of the variables cited above.

Two main clusters, which are more associated with precipitation anomalies over SNEB, were considered and the composite technique was performed to obtain composites of meteorological fields associated with rainy and dry cases. An exclusion criterion was used for the composites: only members, having a correlation above 0.8 with the center of the cluster, were used (Mo and Ghil 1988). The statistical significance of the composites was calculated applying the Student's t-test.

\section{Results}

\section{a. Main rainy season over the $S N E B$}

To verify the rainy season for the period 1979-97, harmonic analysis was applied to the monthly average rainfall of the 99 stations mentioned above and also through histogram monthly rainfall. Figure 3 shows the amplitudes and phases of the first and second harmonic of monthly average rainfall over the sNEB. The ratio between the amplitude of the second and first harmonic is much smaller than 1 in most of the sNEB. Thus the 
TABlE 1. Performatic index (PI), number of elements used in the composites (NC), and number of elements of each cluster (NA) of the rainy and dry patterns on the sNEB.

\begin{tabular}{|c|c|c|c|c|c|c|}
\hline & \multicolumn{3}{|c|}{ Rainy pattern } & \multicolumn{3}{|c|}{ Dry pattern } \\
\hline & PI & $\mathrm{NC}$ & NA & PI & $\mathrm{NC}$ & NA \\
\hline Specific humidity $700 \mathrm{hPa}$ & 1.7 & 168 & 202 & 0.7 & 191 & 470 \\
\hline Outgoing longwave radiation & 1.2 & 120 & 241 & 0.5 & 118 & 378 \\
\hline $850-\mathrm{hPa}$ wind & 1.5 & 162 & 338 & 0.7 & 102 & 468 \\
\hline 200-hPa wind & 2.0 & 155 & 414 & 0.7 & 119 & 190 \\
\hline 200-hPa vorticity & 1.2 & 138 & 338 & 0.7 & 173 & 468 \\
\hline
\end{tabular}

first harmonic or the annual cycle explains most of the variance, with phase angle around $360^{\circ}$, indicating that during the period 1979-97 the maximum of rainfall in most of the region occurs between December and January. These are the same months determined earlier by Kousky and Chu (1978) and Rao and Hada (1990) for different historical periods. Along the northeast coast of sNEB the first harmonic shows that maximum rainfall occurs between April and July, with most of the variance being explained by the annual cycle. Consistent with this, Rao et al. (1993) found that in this region the maximum rainfall occurs between May and June. Along the south coastal areas of sNEB there is little seasonal variation of precipitation, which is probably related to the year-round penetration of cold frontal systems in this area (Kousky 1979). However, if the inland areas are also considered, the main rainy season over the sNEB is November-January (NDJ), as shown in the histogram of the monthly average rainfall (Fig. 4).

\section{b. Large-scale and regional atmospheric patterns}

Hereafter, the patterns associated with positive and negative rainfall anomalies will be referred as rainy and dry patterns, respectively. In the rainy pattern of OLR, low values of OLR extend NW-SE from the Amazon region to the Atlantic Ocean, associated with the cloud band of the SACZ (Fig. 5a). The dry pattern shows a different SACZ configuration, indicating that variability in the position and intensity of the SACZ exerts a strong influence on precipitation over sNEB (Fig. 5c). This feature is reflected in the anomalies, which show negative values in the rainy pattern associated with enhanced convection in the SACZ, and positive values over this region in the dry pattern (Figs. 5b,d). The positive and negative anomalies in the regional OLR analysis show clearly the influence of the SACZ on precipitation over sNEB (Figs. 5e,f).

Positive OLR anomalies over the eastern Amazon and the northeast coast of South America (SA) in the dry pattern indicate weaker than average convection in these areas (Fig. 5d). Suppressed convection is observed over southern SA in the rainy pattern while in the dry pattern there is enhanced convection over southern SA. This out-of-phase configuration between NEB and southern SA has been noticed in several studies (Casarin and Kousky 1986; Kousky and Cavalcanti 1988; NoguésPaegle and Mo 1997; Cavalcanti 2000). Also observed in the OLR anomaly field is the association between the SACZ, South Pacific Convergence Zone (SPCZ), and
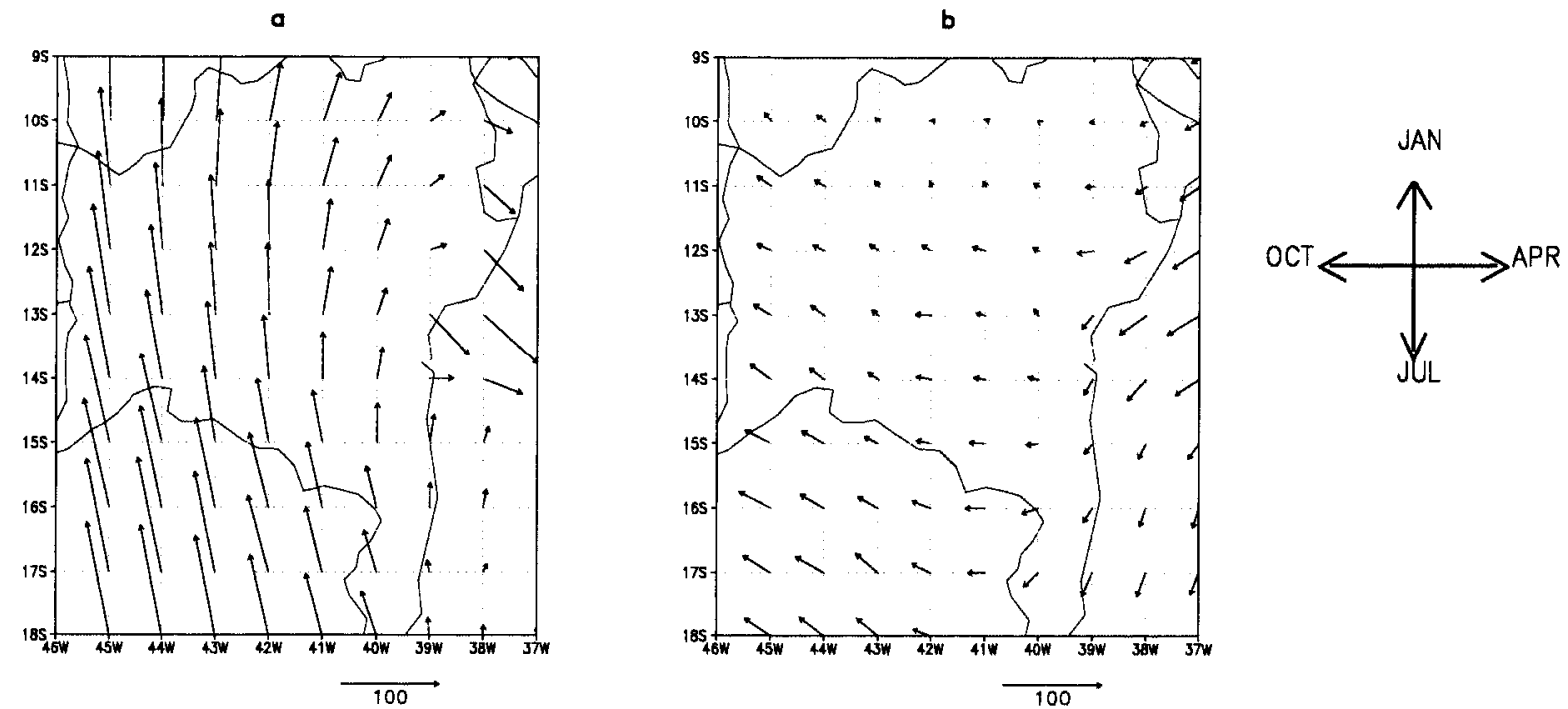

FIG. 3. Amplitudes and phase of the (a) first and (b) second harmonic of the monthly average rainfall on the sNEB, interpolated to a $1^{\circ}$ $\times 1^{\circ}$ grid. The vector clock indicates the phase angle of the vectors. The vertical vector pointing upward indicates a maximum in Jan. 


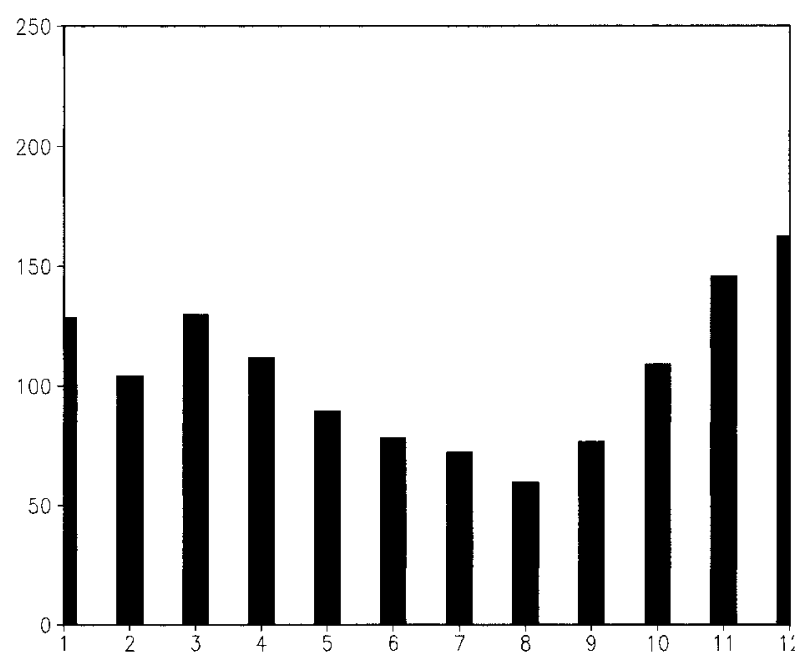

FIG. 4. Histogram of the monthly average rainfall on the sNEB $(\mathrm{mm})$.

the Atlantic ITCZ (Figs. 5b,d). In the rainy pattern the ITCZ is less intense over all of the equatorial Atlantic, while in the dry pattern the ITCZ is more intense in the west tropical Atlantic. Opposite behavior is noted relative to the SPCZ. The rainy pattern is associated with intensification of the tropical sector of the SPCZ and the dry pattern with reduction of convection in this system.

The contrast between the dry and rainy patterns can also be seen in the humidity fields at $700 \mathrm{hPa}$ (Figs. $6 a, c)$ and in the anomalous humidity fields (Figs. 6b,d). The rainy pattern features more moisture over eastern Amazonia and in the region of the SACZ than the dry pattern (Figs. 6a,c). The anomalies are enhanced in the regional analysis, where the patterns show positive anomalies over sNEB oriented NW-SE in the rainy case and with the opposite configuration in the dry case (Figs. $6 e, f)$. The anomalies over sNEB are related to a northward displacement of the SACZ in the rainy pattern and a weakened or southward-displaced SACZ in the dry pattern. It is also evident that the specific humidity anomalies over sNEB are the same sign as those over the Amazon and are opposite in sign to the anomalies farther south. Over the tropical Pacific the humidity is greater in the dry pattern than in the rainy pattern. Thus specific humidity anomalies over sNEB have an inverse relationship to those of equatorial Pacific (Figs. 6b,d), which can show a relationship between ENSO and rainfall variability over sNEB.

In order to verify the large-scale and low-frequency influence on these patterns, the OLR anomalies were calculated for the El Niño periods of NDJ 1982/83, 1986/87, 1994/95, and 1997/98 (Fig. 7), and La Niña periods for NDJ 1984/85, 1995/96, 1988/89, and 1999/ 2000 (Fig. 8). It can be seen that the configuration of El Niño has similar characteristics to the dry pattern, with positive OLR anomalies in the region of the SACZ and negative anomalies over the equatorial Pacific Ocean. In La Niña episodes the convection is above average only in 1984/85 and 1999/2000. In 1995/96 there are normal conditions over the sNEB region and below average convection in 1988/89. The above normal precipitation over NEB, in La Niña episodes seems to be associated with the influence of synoptic systems that can affect the convection in the region when they are not submitted to the large-scale subsidence that occurs in El Niño episodes.

The influence of the NEB upper-level cyclonic vortex on the sNEB precipitation can be seen in the vorticity anomaly fields (Fig. 9). The cyclonic vorticity associated with the NEB upper-level vortex is located over the Atlantic Ocean in the rainy pattern and over eastern Amazonia and NEB in the dry pattern. This system is characterized by subsidence in the central part (Kousky and Gan 1981), inhibiting the convection when it is over the region. In this anomalous vorticity pattern a wave train extends from the Pacific Ocean to NEB in both cases, but with different phases (Figs. 9a,b). These patterns are similar to the high-frequency patterns of meridional wind that are associated with the displacement of frontal systems over South America, as discussed by Kousky and Cavalcanti (1997) and Cavalcanti and Kayano (1999). The results of the present study indicate that besides the influence of the upper-level vortex position on the precipitation over sNEB there is also the influence of frontal systems, which follow the wave train pattern. These results agree with those of Kousky (1979) who showed the relation between precipitation over sNEB and the arrival of frontal systems. The wave train pattern can also contain the center of action associated with blocking situation in the southeast South Pacific, where an anticyclonic vorticity occurs in the rainy pattern. In this way, the blocking situation would be related to excessive rainfall over sNEB, which is consistent with the anomalous trough over southeastern South America and anticyclonic vorticity associated with excessive convection over sNEB.

In the regional patterns of vorticity at high levels (Figs. 9c-f) the main differences between the wet and dry patterns are related to the Bolivian high and the NE trough. The Bolivian high is displaced southward and the NE trough is over the NE region in the dry pattern. In the wet pattern the anticyclonic vorticity of the Bolivian high extends over all of tropical South America and the NE trough is located over the Atlantic Ocean. The regional anomaly fields enhance these characteristics.

One of the contrasts between dry and wet cases, as seen in the high-level wind field, is in the position and intensity of the Bolivian high (Fig. 10). This system is more intense and farther north in the wet pattern (Figs. 10a,b). This implies a strong anticyclonic circulation and stronger winds over subtropical South America in the wet case. This configuration is also related to the SACZ, which was previously associated with upper sub- 
(a) rainy

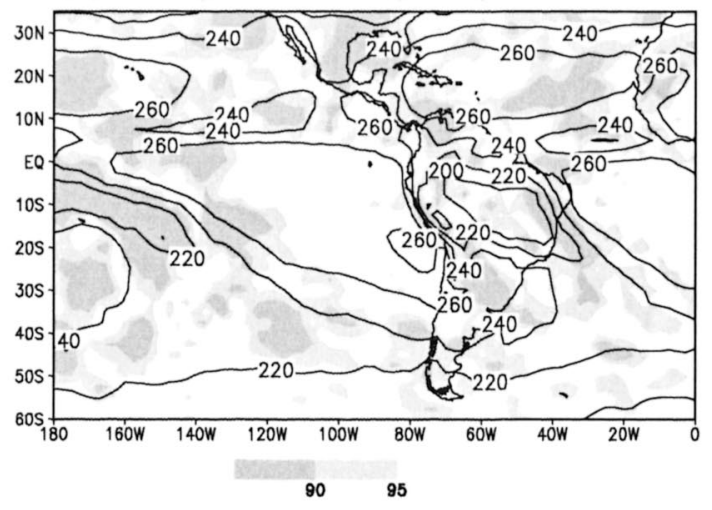

(b) rainy OLR anomaly $\left(\mathrm{Wm}^{-2}\right)$

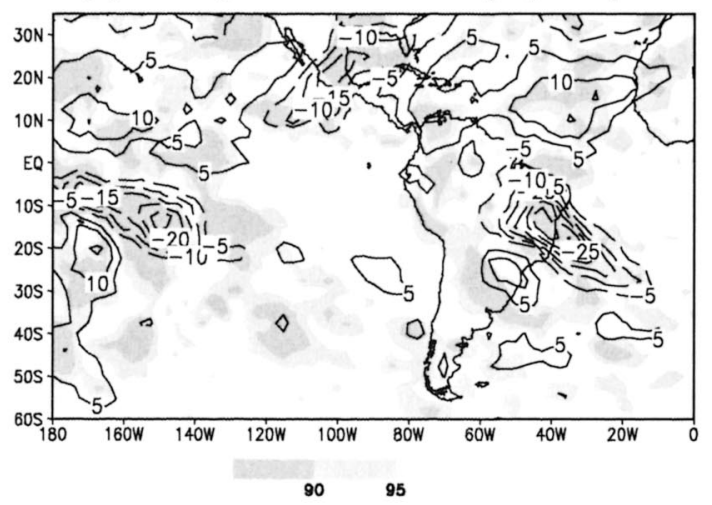

(e) rainy OLR anomaly $\left(\mathrm{Wm}^{-2}\right)$

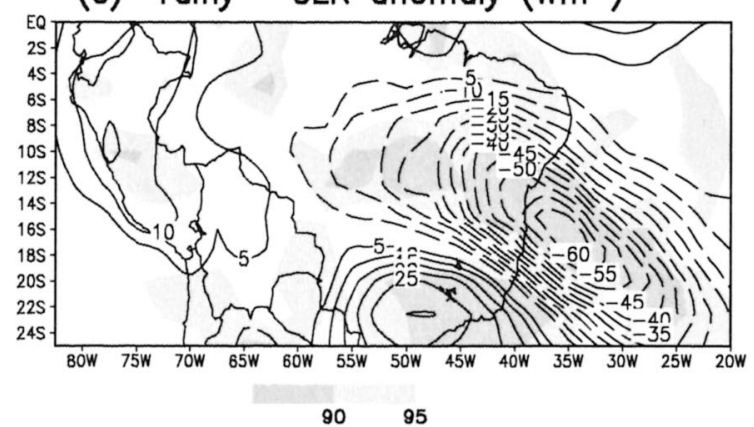

(c) dry OLR $\left(W m^{-2}\right)$

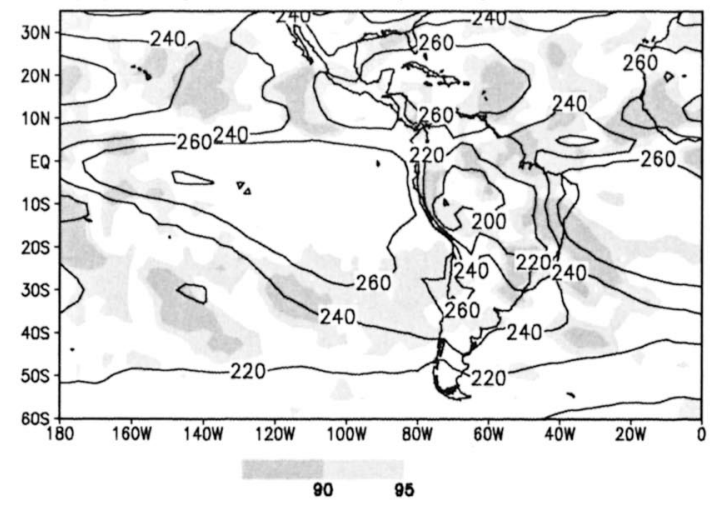

(d) dry OLR anomaly $\left(\mathrm{Wm}^{-2}\right)$

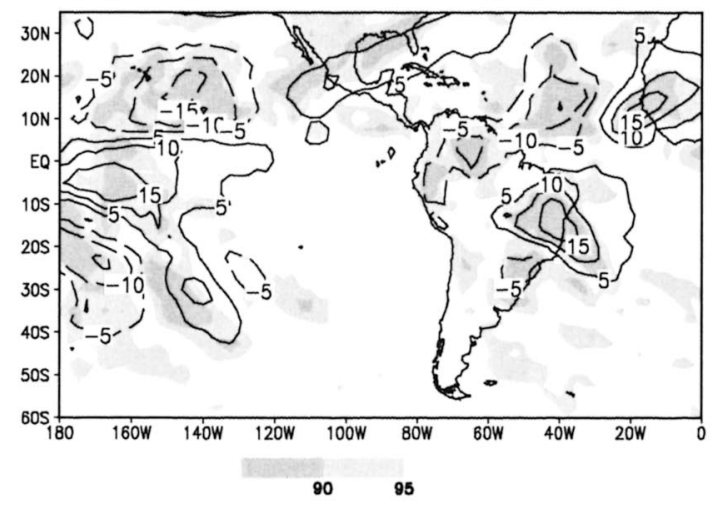

(f) dry OLR anomaly $\left(\mathrm{Wm}^{-2}\right)$

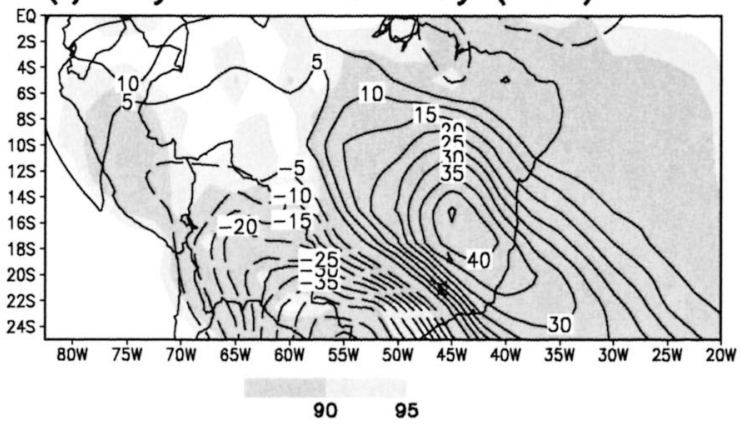

FIG. 5. Composites of (a) and (c), OLR fields (contour line $20 \mathrm{~W} \mathrm{~m}^{-2}$ ) and (b), (d), (e), and (f) anomaly OLR fields (contour line $5 \mathrm{~W}$ $\mathrm{m}^{-2}$ ) associated with the rainy [(a), (b), and (e)] and dry patterns [(c), (d) and (f)] over the sNEB for NDJ from 1979/80 to 1996/97. Regional patterns are shown in (e) and (f). The dashed lines (solid) represent negative (positive) OLR anomalies. The shaded areas represent the statistical significance of the composites.

tropical jets by Kodama (1993). The differences observed in the eastern South Pacific suggest that the strong bifurcation of the flow in the wet case is associated with the confluence and strengthening of wind over South America. In this case there is also a strong wavy flow at middle and subtropical latitudes that affects the Bolivian high circulation. The intensification and weakening of the Bolivian high can be seen in the anomalous fields (Figs. 10c,d). The regional patterns enhance the characteristics of the Bolivian high and the northeast upper-level vortex (Fig. 11). The Bolivian high is displaced northeastward and the upper-level trough is located over the tropical Atlantic in the rainy pattern (Fig. 11a). In the dry pattern the Bolivian high is displaced southward and the upper vortex is located over Northeast Brazil (Fig. 11b). The anomalous patterns enhance these characteristics (Figs. 11c,d).

The main differences between the rainy and dry patterns of the low-level wind field are found in the position of the subtropical Atlantic anticyclone, in the intensity 


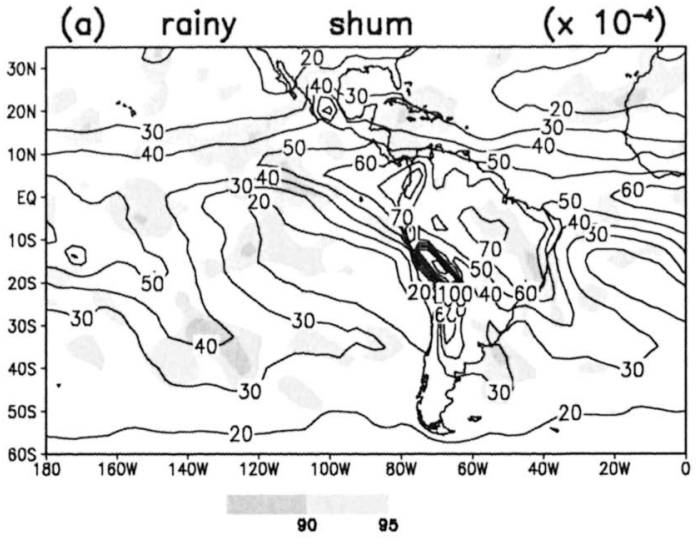

(b) rainy shum anomaly $\left(x 10^{-4}\right)$

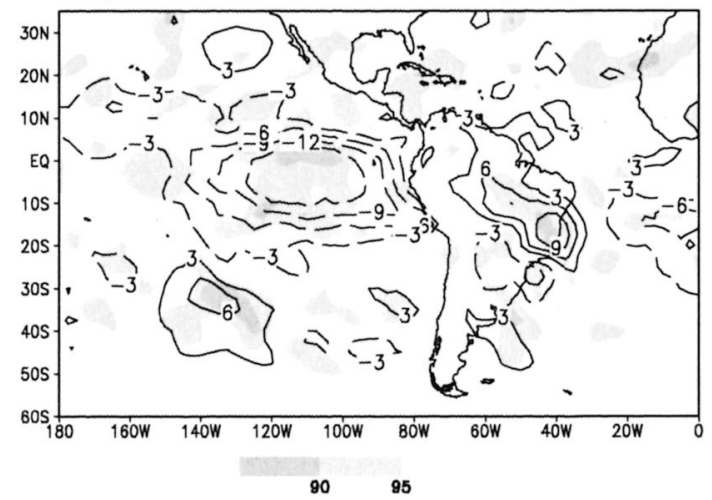

(e) rainy shum anomaly $\left(\times 10^{-4}\right)$

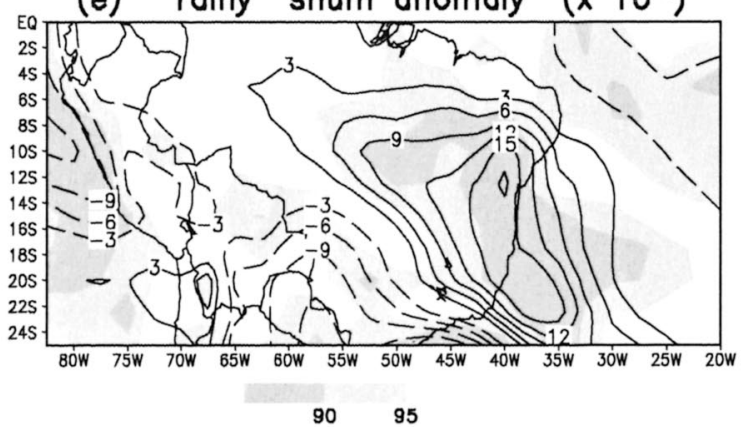

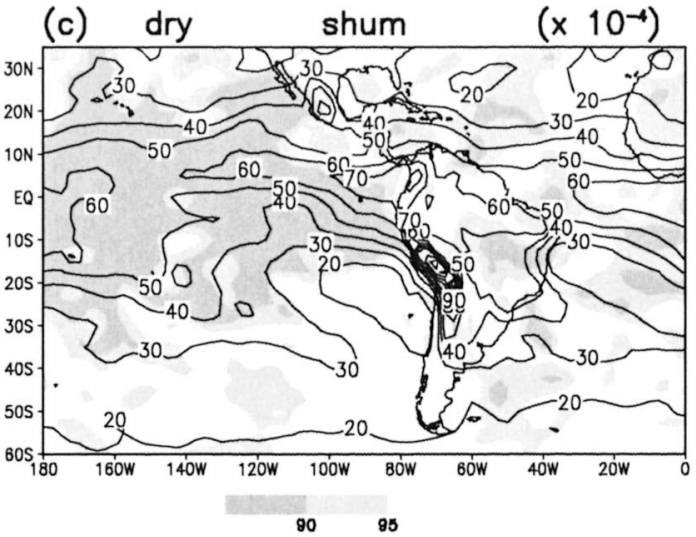

(d) dry shum anomaly $\left(\times 10^{-4}\right)$
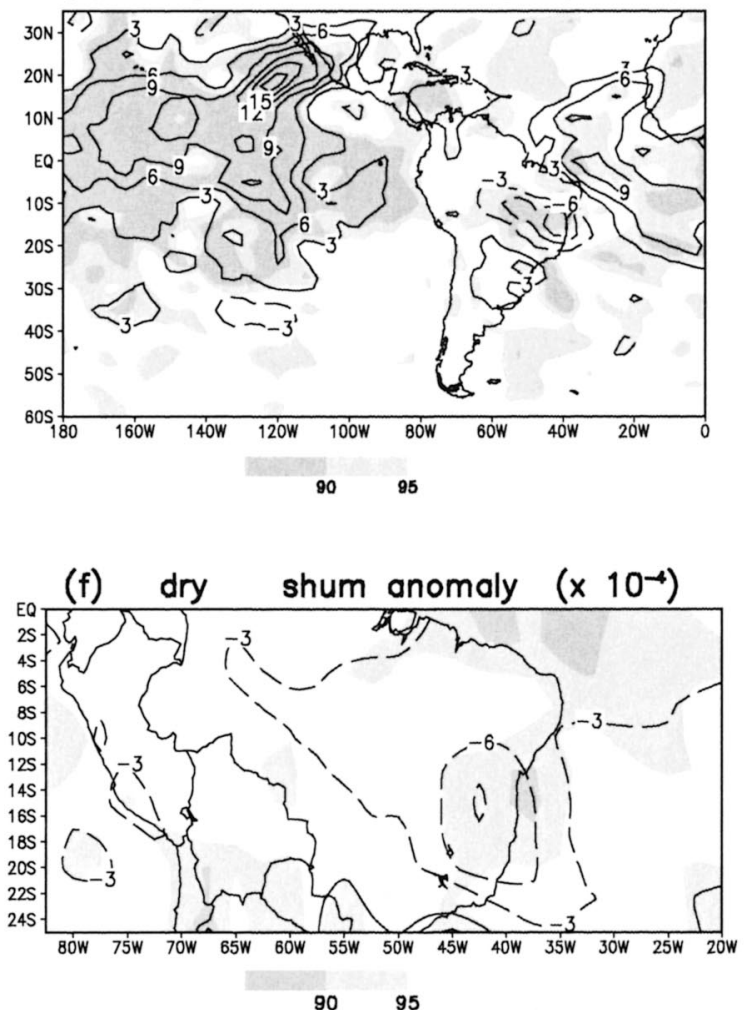

FIG. 6. As in Fig. 5 but for specific humidity fields at $700 \mathrm{hPa}$ (from NDJ 1979/80 to 1995/96). (a) and (c), Contour line $30 \times 10^{-4}$ and (b), (d), (e), and (f) contour line $3 \times 10^{-4}$.

of the Atlantic trade winds and in the flow over SA (Fig. 12). In the rainy pattern the South Atlantic anticyclone is displaced eastward and there is convergence of winds over SA and the Atlantic Ocean far north of the convergence observed in the dry pattern, where the subtropical Atlantic anticyclone is displaced westward. In the anomalous field, alternating cyclonic and anticyclonic circulation flows extend from the Pacific Ocean eastward to SA in both the wet and dry cases, resulting in the establishment of cyclonic circulation (wet pattern) and anticyclonic circulation (dry pattern) over sNEB. The differences between the wet and dry cases are stressed in the regional analysis (Fig. 13). In the rainy pattern there is weakening of the trade winds with lowlevel flow from the Amazonia region toward sNEB. In the dry pattern, the opposite situation occurs with intensification of winds over sNEB and flow from Amazonia shunted farther south toward southeastern Brazil. The contribution of the Amazon convection in determining the preferred position of the SACZ was considered by Liebmann et al. (1999). Enhanced low-level convergence in the region of the SACZ was also related to the Amazon convection by Figueroa et al. (1995). The results are also consistent with those found by Chu 
NDJ $1982 / 83$

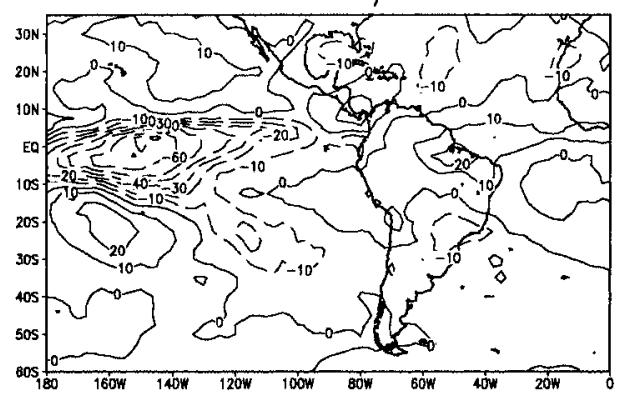

NDJ $1994 / 95$

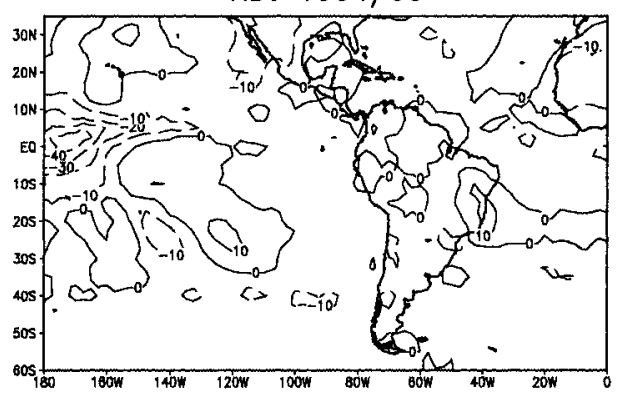

NDJ $1986 / 87$

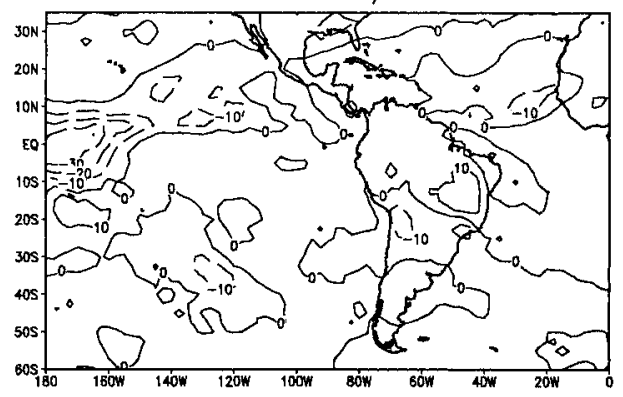

NDJ $1997 / 98$

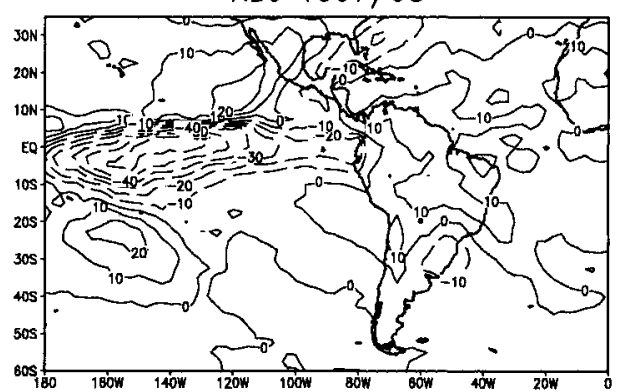

FIG. 7. OLR anomalies (contour line $10 \mathrm{~W} \mathrm{~m}^{-2}$ ) for NDJ 1982/83, 1986/87, 1994/95, and $1997 / 98$.

(1982) who showed, using radiosonde data and monthly precipitation of November and December over the SNEB, that in the dry years the South Atlantic anticyclone and southeast trade winds were stronger than in the rainy years. These patterns are consistent with the influence of the SACZ on SNEB. The direction of lowlevel flow and the moisture transport are important to the location of the SACZ. Nogués-Paegle and Mo
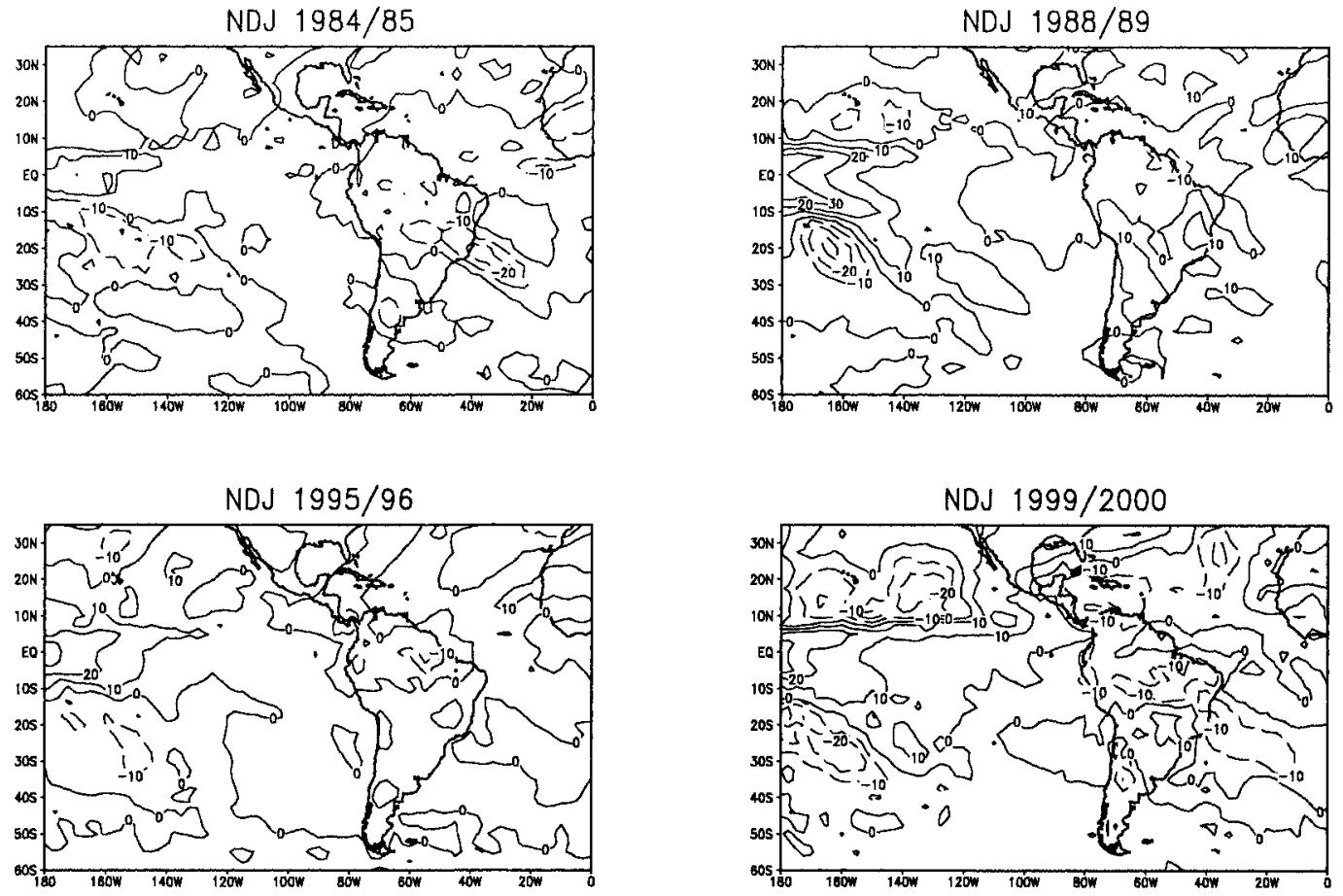

FIG. 8. OLR anomalies (contour line $10 \mathrm{~W} \mathrm{~m}^{-2}$ ) for NDJ 1984/85, 1988/89, 1995/96, and 1999/2000. 
(a) rainy vort anomaly $\left(x 10^{-0}\right)$

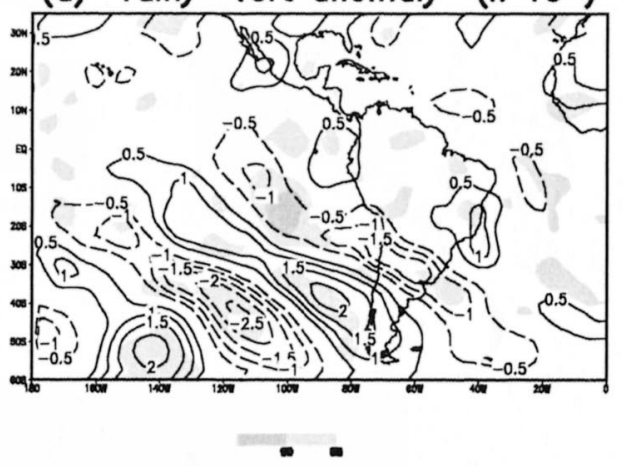

(c) rainy vort $\left(s^{-1} \times 10^{-6}\right)$

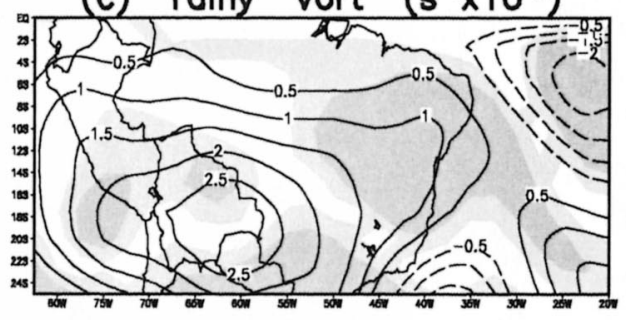

$\cdot \cdot$

(e) rainy vort anomaly $\left(\mathrm{s}^{-1} \times 10^{-0}\right)$

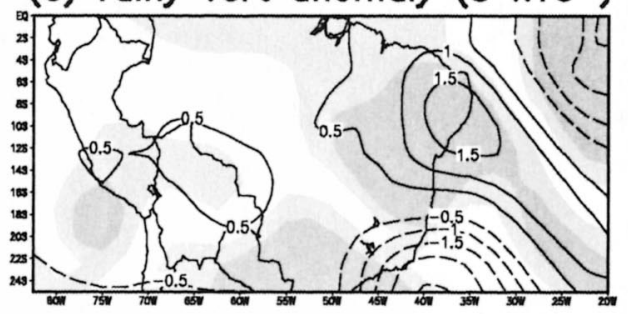

$\infty$ (b) dry vort anomaly (x 10-0)

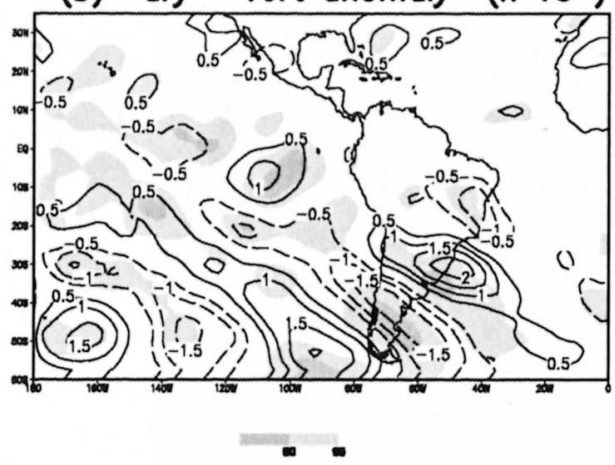

(d) dry vort $\left(s^{-1} \times 10^{-b}\right)$

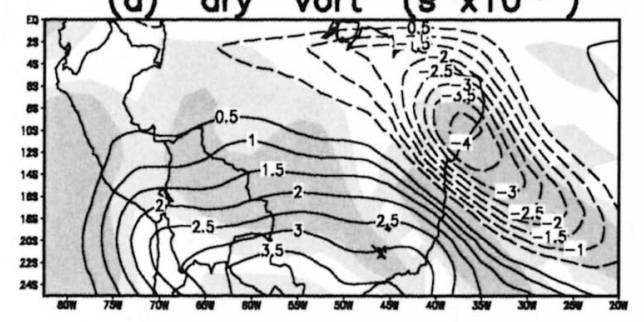

(f) dry vort anomaly $\left(8^{-1} \times 10^{-6}\right)$
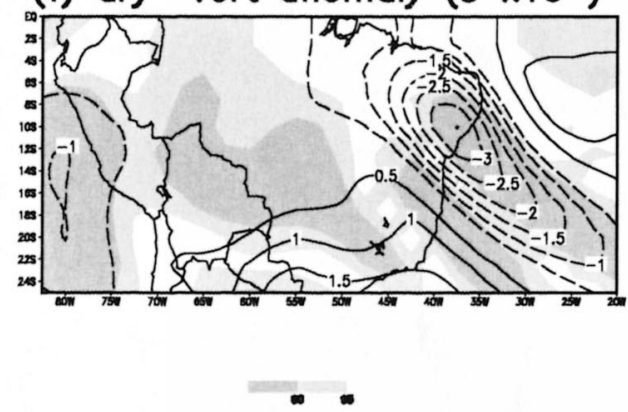

FIG. 9. (a), (b), (e), and (f), Relative vorticity anomaly (contour line $0.5 \times 10^{-6} \mathrm{~s}^{-1}$ ) and relative vorticity (contour line $\left.0.5 \times 10^{-5} \mathrm{~s}^{-1}\right)$ at $200 \mathrm{hPa}$ associated with the rainy (a), (c), and (e) and dry (b), (d), and (f) patterns over the sNEB from NDJ for $1979 / 80$ to $1996 / 97$.

(1997) related excessive rainfall over subtropical SA to strong northerly flow at low levels, and Kodama (1992) indicated that the moist transport by low-level winds is an important mechanism in the moisture supply to the convergence zones. The results show that besides the upper-level influence, the location and strengthening of the SACZ is controlled by the west periphery of the South Atlantic anticyclone and the flow from the Amazon region. The location of the SACZ over sNEB is associated with the weakening and/or displacement of the South Atlantic anticyclone eastward and consequently with weaker southeast trade winds.

\section{Conclusions}

The characteristics of the atmospheric circulation associated with rainfall variability over sNEB were determined by applying PCA coupled with cluster analysis in the NCEP-NCAR reanalysis data and OLR associated with daily rainfall data of NDJ, the main rainy period of this region. The two main patterns associated with positive and negative precipitation anomalies of several variables over the sNEB were obtained for extended and regional domains. The results show strong relations between rainfall variability over the SNEB and the posi- 
(a) rainy wind $200 \mathrm{hPo}(\mathrm{m} / \mathrm{s}) \quad \mathrm{Pl}=2.0$

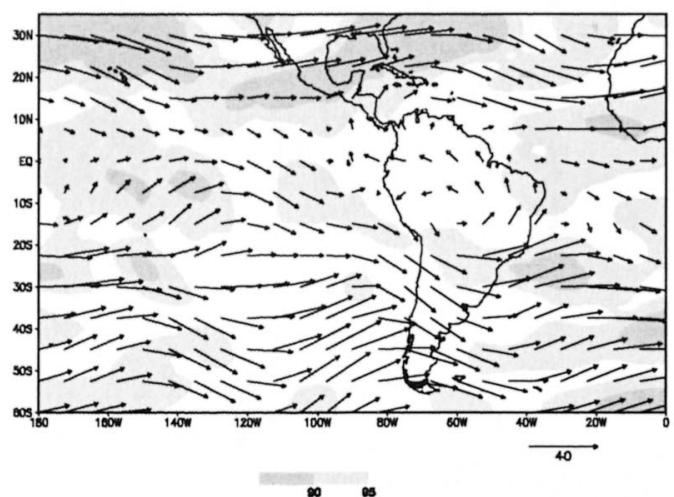

(c) roiny wind200 onomaly $\mathrm{Pl}=2.0$

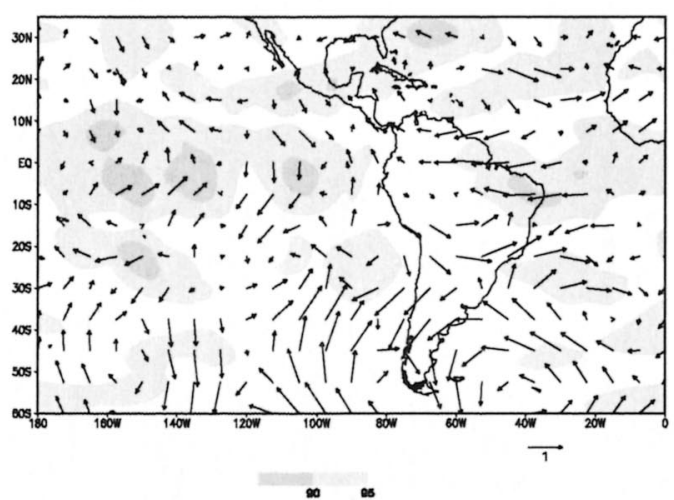

(b) dry wind $200 \mathrm{hPo}(\mathrm{m} / \mathrm{s}) \quad \mathrm{Pl}=0.7$

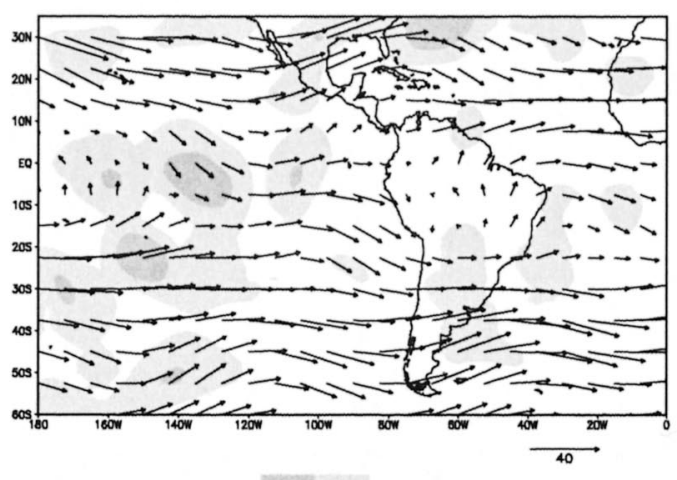

(d) dry wind200 onomaly $\mathrm{Pl}=0.7$

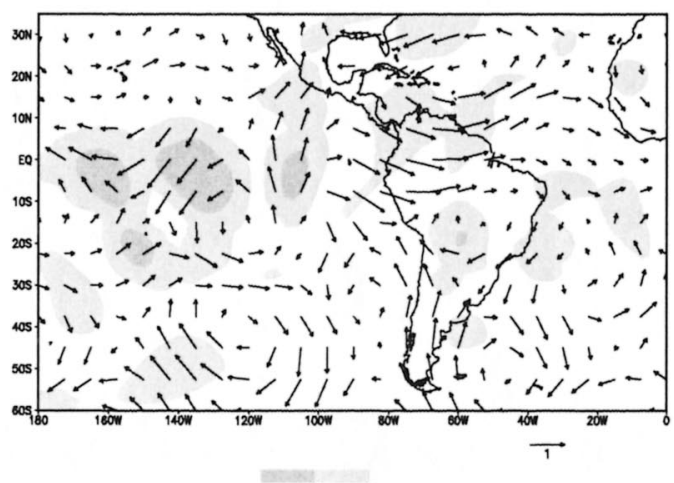

FIG. 10. The 200-hPa wind associated with the (a) and (c) rainy and (b) and (d) dry patterns over the sNEB from NDJ for 1979/80 to 1996/97. (a) and (b) Units are $\mathrm{m} \mathrm{s}^{-1}$, and (c) and (d) units are adimensional.
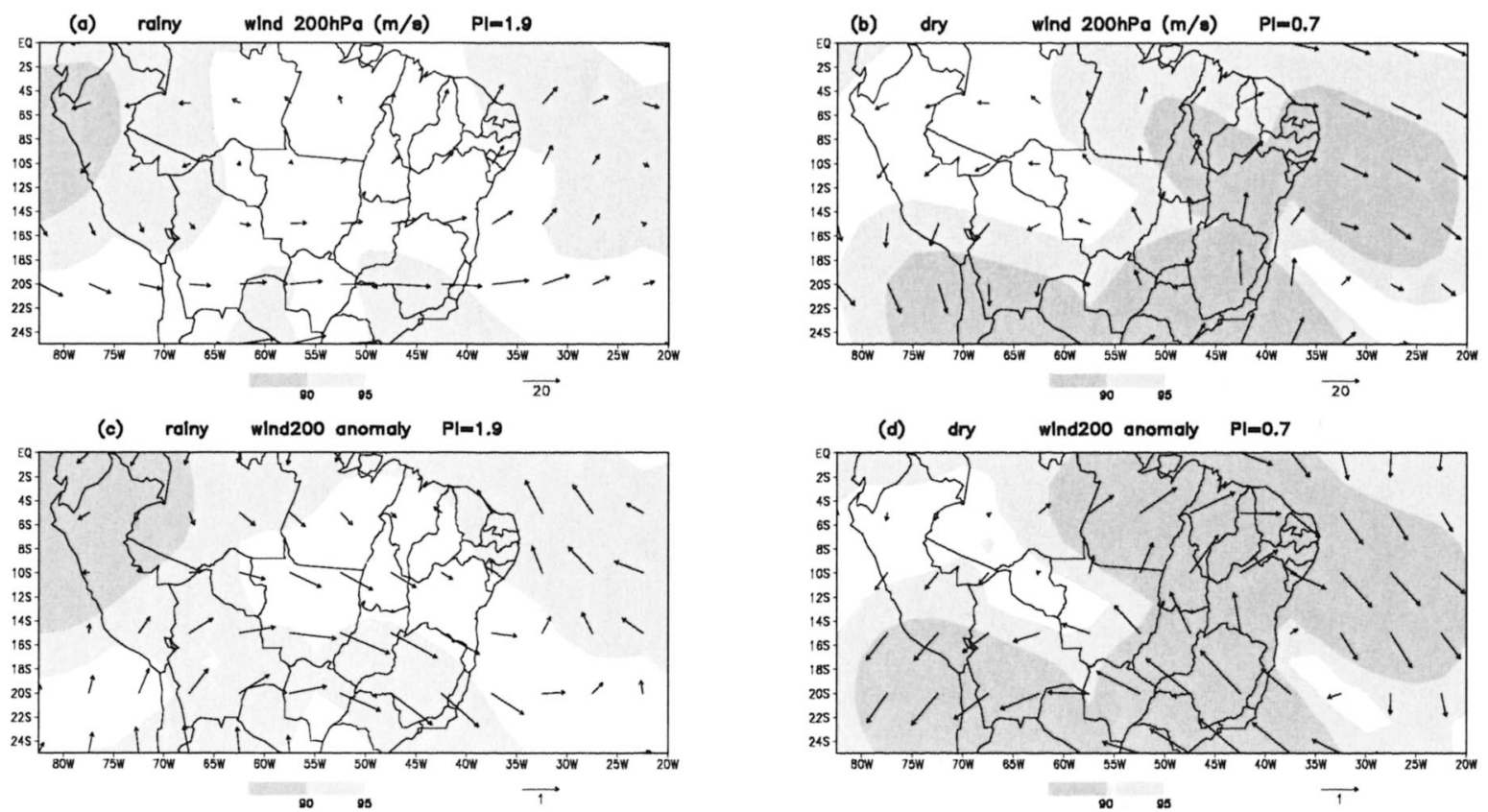

FIG. 11. As in Fig. 10 but for regional patterns. 
(a) roiny wind $850 \mathrm{hPo}(\mathrm{m} / \mathrm{s}) \quad \mathrm{Pl}=1.5$

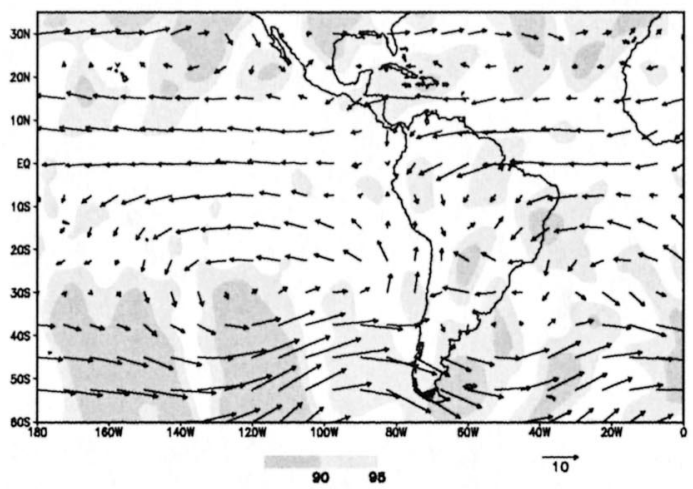

(b) rainy wind850 onomaly $\mathrm{PI}=1.5$

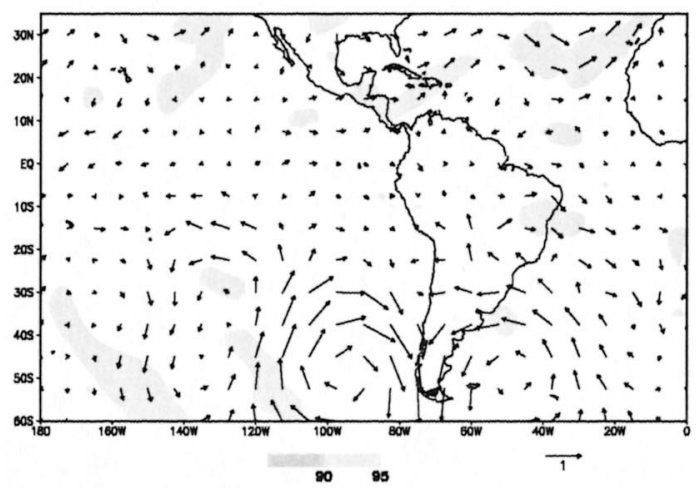

(c) dry wind $850 \mathrm{hPa}(\mathrm{m} / \mathrm{s}) \quad \mathrm{Pl}=0.7$

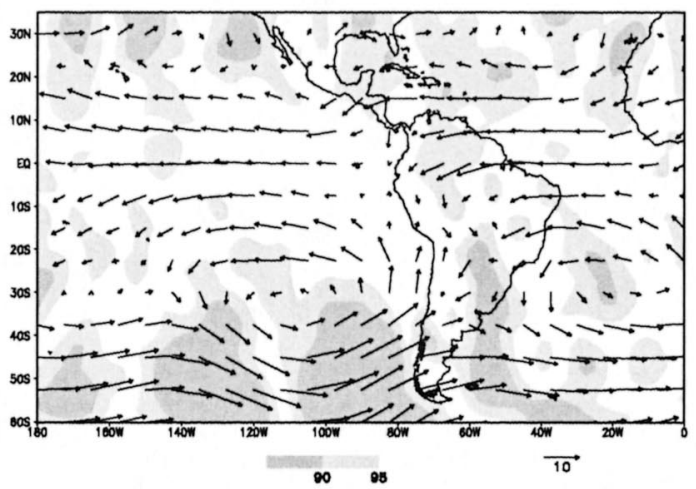

(d) dry wind850 anomaly $P I=0.7$

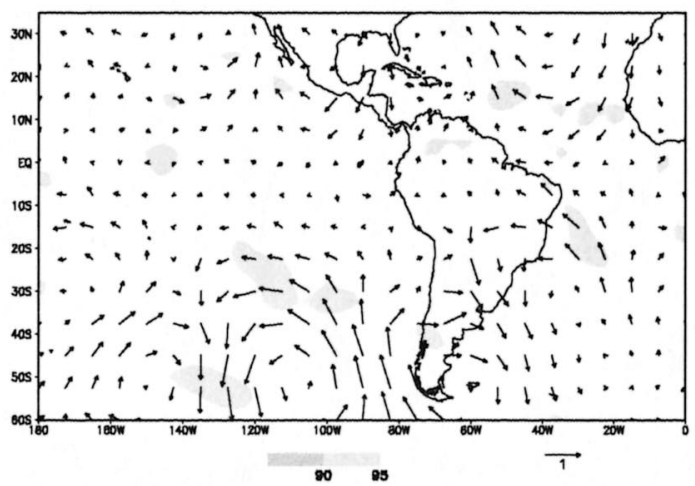

FIG. 12. The $850-\mathrm{hPa}$ wind associated with the (a) and (c) rainy and (b) and (d) dry patterns over the sNEB from NDJ for $1979 / 80$ to 1996/97. (a) and (b) Units are $\mathrm{m} \mathrm{s}^{-1}$ and (c) and (d) units are adimensional.
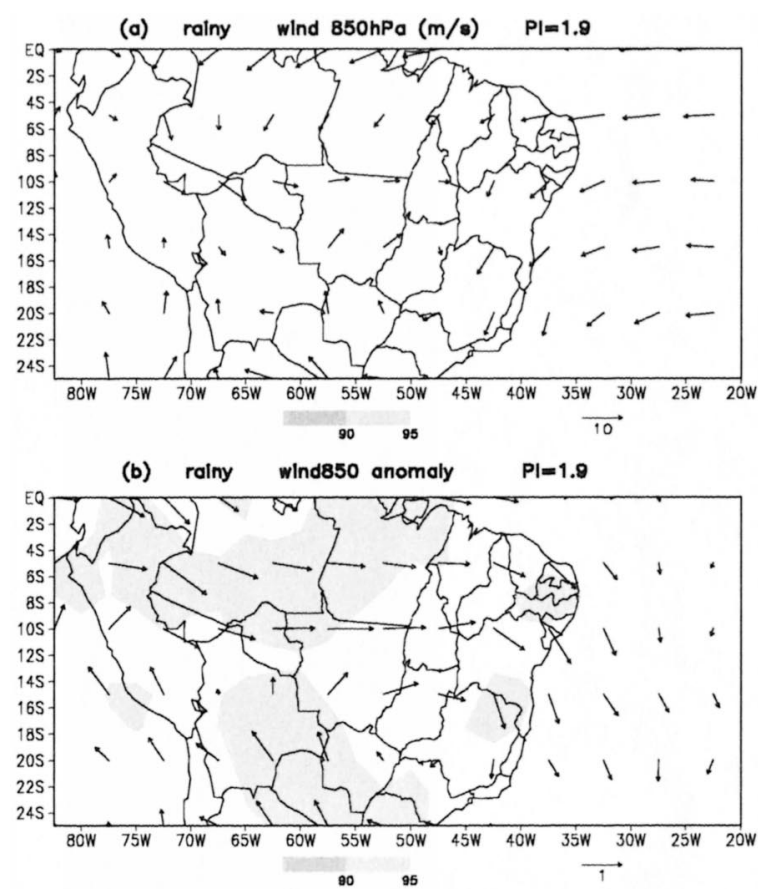
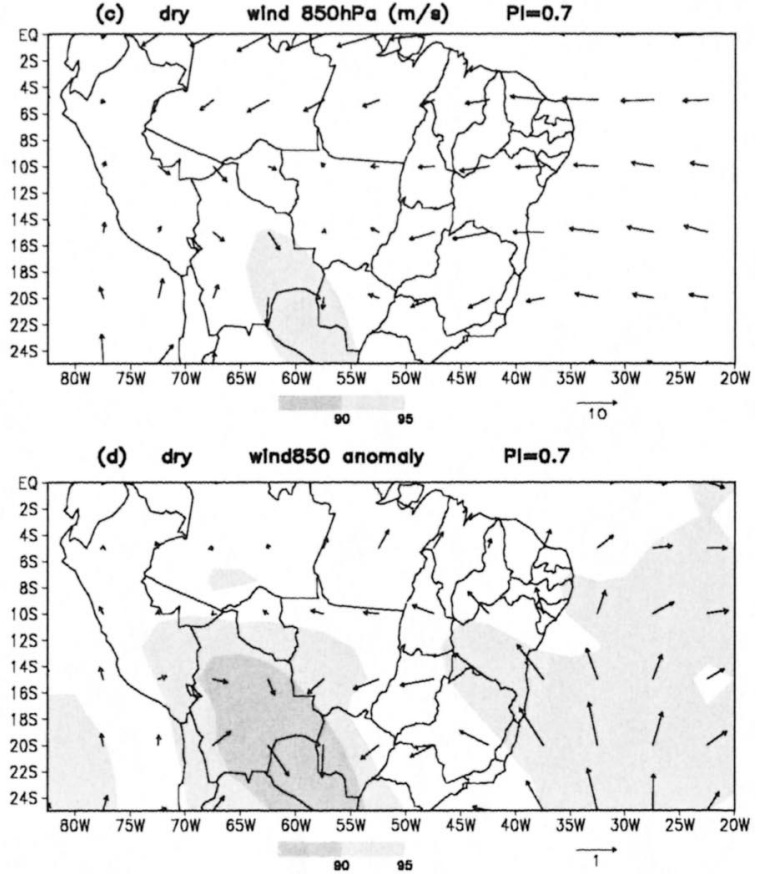

FIG. 13. As in Fig. 12 but for regional patterns. 
tions of synoptic systems and the ENSO phenomenon. The negative rainfall anomalies over the SNEB are related to the negative phase of ENSO (El Niño), while the positive anomalies can be associated with the occurrence of synoptic systems. The El Niño influence can occur directly through an east-west variation of the local Walker circulation cell that can affect the conditions of the Amazon and northeast or through teleconnections with circulation features at higher latitudes.

A relationship between the rainfall anomalies over the sNEB and the atmospheric anomalies over Amazon region was found. The rainy pattern was associated with convection on the eastern Amazon and consequently with an eastward displacement of the Bolivian high. In the wet case the NEB trough was located over the Atlantic Ocean, allowing the displacement of the SACZ northward, which affected sNEB. In the dry pattern the NEB trough was close to the northeast coast, the Bolivian high was displaced westward, and the SACZ was displaced southward. The main features of the wind field at high level are the wavy behavior of the flow at middle latitudes, intense confluence over the west coast of South America, and the positions of the Bolivian high and the NEB vortex. Different phases of wave trains over Pacific and South America were associated with the rainy and dry patterns.

At low levels the noteworthy difference between the rainy and dry pattern is identified in the intensity and direction of the flow from the Amazon and from the southeast trade winds. In the rainy pattern the wind flows from the Amazon to the SNEB, and the South Atlantic anticyclone is displaced eastward with trade winds less intense over SA. This configuration results in moisture convergence over sNEB, allowing for the development and organization of the SACZ north of its normal position. In the dry pattern the South Atlantic anticyclone is displaced westward, intensifying the southeast trade winds over Brazil. In this case the wind flows from the Amazon toward the southeast, displacing the SACZ southward. Thus, the southern Northeast Brazil region is affected by anomalies of the main meteorological summer systems over Brazil, which are influenced by the atmospheric conditions associated, in part, with oceanic conditions in the tropical Pacific.

Acknowledgments. The authors are grateful to Dr. Vernon E. Kousky for useful comments and suggestions. We also thank the anonymous reviewers for their suggestions. Daily station datasets obtained from the Brazilian National Agency for Electric Energy and Hydrological Resource Management of Bahia State. This work represents a portion of R. R. Chaves's master's dissertation at INPE and was supported by CAPES.

\section{REFERENCES}

Casarin, D. P., and V. E. Kousky, 1986: Anomalias de precipitação no Sul do Brasil e variações na circulação atmosférica (Precip- itation anomalies in south Brazil and variations in the atmospheric circulation). Rev. Bras. Meteor., 1, 83-90.

Cavalcanti, I. F. A., 1986: The anomalous rainfall in Northeast Brazil in 1985. Extended Abstracts, Second Int. Conf. on Southern Hemisphere Meteorology, Wellington, New Zealand, Amer. Meteor. Soc., 446-448.

—_ 2000: Teleconnections patterns orographically induced in model results and from observational data in the austral winter of the southern hemisphere. Int. J. Climatol., 20, 1191-1206.

__ , and M. T. Kayano, 1999: High-frequency patterns of the atmospheric circulation over the Southern Hemisphere and South America. Meteor. Atmos. Phys., 69, 179-193.

Chu, P. S., 1982: Diagnostics of climate anomalies in tropical Brazil. Ph.D. thesis, University of Wisconsin-Madison, 148 pp.

Figueroa, S. N., P. Satyamurty, and P. L. Silva Dias, 1995: Simulations of the summer circulation over South American region with an Eta coordinate model. J. Atmos. Sci., 52, 1573-1584.

Gong, X., and M. B. Richman, 1992: An examination on methodological issues in clustering North American precipitation. Proc. Fifth Int. Meeting on Statistical Climatology, Toronto, ON, Canada, Environment Canada, Atmospheric Environment Service, J103-J108.

Hartigan, J. A., and M. A. Wong, 1979: Algorithm AS 136: A Kmeans clustering algorithm. Appl. Stat., 28, 100-108.

Hastenrath, S., and L. Heller, 1977: Dynamics of climatic hazards in northeast Brazil. Quart. J. Roy. Meteor. Soc., 103, 77-92.

Kalkstein, L. S., G. Tan, and J. Skindlov, 1987: An evaluation of three clustering procedures for use in synoptic climatological classification. J. Climate Appl. Meteor., 26, 717-729.

Kalnay, E., and Coauthors, 1996: The NCEP/NCAR 40-Year Reanalysis Project. Bull. Amer. Meteor. Soc., 77, 437-471.

Kodama, Y., 1992: Large-scale common features of subtropical precipitation zones, (the Baiu frontal zone, the SPCZ, and SCAZ). Part I: Characteristics of subtropical frontal zones. J. Meteor. Soc. Japan, 70, 813-836.

__ 1993: Large-scale common features of subtropical precipitation zones, (the Baiu frontal zone, the SPCZ, and SCAZ). Part II: Conditions of the circulation for generating the STCZs. J. Meteor. Soc. Japan, 71, 581-610.

Kousky, V. E., 1979: Frontal influences on northeast Brazil. Mon. Wea. Rev., 107, 1140-1153.

- 1980: Diurnal rainfall variation in northeast Brazil. Mon. Wea. Rev., 108, 488-498.

_ 1985: Atmospheric circulation changes associated with rainfall anomalies over tropical Brazil. Mon. Wea. Rev., 113, 1951-1957.

_, 1988: Pentad outgoing longwave radiation climatology for the South American sector. Rev. Bras. Meteor., 3, 217-231.

-, and P. S. Chu, 1978: Fluctuations in annual rainfall for northeast Brazil. J. Meteor. Soc. Japan, 56, 457-465.

_- and M. A. Gan, 1981: Upper tropospheric cyclonic vortices in the tropical South Atlantic. Tellus, 33, 538-551.

—_ and I. F. A. Cavalcanti, 1988: Pentad outgoing longwave radiation climatology for the South American sector. Rev. Bras. Meteor., 3, 217-231.

_- and I. F. A. Cavalcanti, 1997: The principal modes of highfrequency variability over the South American region. Preprints, Fifth Int. Conf. on Southern Hemisphere Meteorology and Oceanography, Pretoria, South Africa, Amer. Meteor. Soc., 226227.

__, M. T. Kayano, and I. F. A. Cavalcanti, 1984: A review of the Southern Oscillation: Oceanic-atmospheric circulation changes and related rainfall anomalies. Tellus, 36A, 490-504.

Liebmann, B., and C. A. Smith, 1996: Description of a complete (interpolated) outgoing longwave radiation dataset. Bull. Amer. Meteor. Soc., 77, 1275-1277.

—_, G. N. Kiladis, J. A. Marengo, T. Ambrizzi, and J. D. Glick, 1999: Submonthly convective variability over South America and the South Atlantic convergence zone. J. Climate, 12, 18771891. 
Mo, K., and M. Ghil, 1988: Cluster analysis of multiple planetary flow regimes. J. Geophys. Res., 93 (D9), 10 927-10 952.

Molteni, F., S. Tibaldi, and T. N. Palmer, 1990: Regimes in wintertime circulation over northern extratropics. I: Observational evidence. Quart. J. Roy. Meteor. Soc., 116, 31-67.

Moura, A. D., and J. Shukla, 1981: On the dynamics of droughts in northeast Brazil: Observations, theory and numerical experiments with a general circulation model. J. Atmos. Sci., 38, 26532675.

Nobre, C. A., and L. C. B. Molion, 1988: The climatology of drought and drought prediction. The Impact of Climate Variations on Agriculture, M. L. Parry, T. R. Carter, and N. T. Konijn, Eds., Vol. 2, Kluwer Academic, 305-323.

Nobre, P., and J. Shukla, 1996: Variations of sea surface temperature, wind stress, and rainfall over the tropical Atlantic and South America. J. Climate, 9, 2464-2479.

Nogués-Pagle, J., and K. C. Mo, 1997: Alternating wet and dry conditions over South America during summer. Mon. Wea. Rev., 125, 279-291.

Rao, V. B., and K. Hada, 1990: Characteristics of rainfall over Brazil: Annual variations and connections with the Southern Oscillation. Theor. Appl. Climatol., 42, 81-91.
— M. C. Lima, and S. H. Franchito, 1993: Seasonal and interannual variations of rainfall over eastern northeast Brazil. $J$. Climatol., 6, 1754-1763.

— I. I. F. A. Cavalcanti, and K. Hada, 1996: Annual variations of rainfall over Brazil and water vapor characteristics over South America. J. Geophys. Res., 101 (D21), 26 539-26 551.

—, L. D. A. Sá, S. H. Franchito, and K. Hada, 1997: Interannual variations of rainfall and corn yield in Northeast Brazil. Agric. For. Meteor., 85, 63-74.

Silva Dias, P. L., W. H. Schurbet, and M. De Maria, 1983: Large scale response of the tropical atmosphere to transient convection. J. Atmos. Sci., 40, 2689-2707.

Tanajura, C. A. S., 1996: Modeling and analysis of the South American summer climate. Ph.D. thesis, University of Maryland, $164 \mathrm{pp}$.

Trenberth, K., 1997: The definition of El Niño. Bull. Amer. Meteor. Soc., 78, 2771-2777.

Wilks, D. S., 1995: Statistical Methods in the Atmospheric Sciences: An Introduction. Academic Press, $467 \mathrm{pp}$.

Zhang, X., X. L. Wang, and J. Corte-Real, 1997: On the relationships between daily circulation patterns and precipitation in Portugal. J. Geophys. Res., 102 (D21), 13 495-13 507. 